\title{
Inhibitory effect of timolol on topical glucocorticoid-induced skin telangiectasia
}

\author{
YAN-FEI LI ${ }^{1 *}$, XIAO-YAN CHEN ${ }^{2}$ and TIE-CHI LEI ${ }^{1 *}$ \\ ${ }^{1}$ Department of Dermatology, Renmin Hospital of Wuhan University, Wuhan, Hubei 430060; ${ }^{2}$ Department of Pathology, \\ Baotou Medical College, Baotou, Inner Mongolia Autonomous Region 014010, P.R. China
}

Received November 11, 2017; Accepted June 12, 2018

DOI: $10.3892 / \mathrm{mmr} .2018 .9266$

\begin{abstract}
The aim of the present study wasto investigate the potential inhibitory effect of timolol on topical glucocorticoid-induced skin telangiectasia. In rabbits, flumethasone ointment was used to induce skin telangiectasia in the inner ear. Subsequently, timolol maleate $(0.5 \%)$ eye drops (TMEDs) were administered twice daily for 4 weeks. Expression of the antibacterial peptides 37 -amino acid peptide (LL-37) and kallikrein-5 (KLK5) was detected using quantitative polymerase chain reaction (PCR) and semi-quantitative reverse transcription-PCR. In patients with facial skin telangiectasia, one cheek of each patient was assigned to a treatment group and the other to a control group. For the treatment group cheeks, topical application of TMEDs was combined with $0.1 \%$ tacrolimus ointment once or twice daily for 8 weeks. The control group cheeks were administered with $0.1 \%$ tacrolimus ointment alone. Alterations in lesions were recorded by dermoscopy, and the L, a and b values of lesions were measured, based on the Commission Internationale de l'Éclairage system, with a chromameter prior to and at 1,2, 4 and 8 weeks following treatment. The results indicated that erythema, papules and telangiectasia were significantly diminished following 4 weeks of treatment with TMEDs in rabbits. Notably, the expression of LL-37 and KLK5 mRNA was increased in the negative control group; however, it was decreased in the trial and blank groups. Clinical and dermoscopy images demonstrated that erythema was reduced in the 2 groups for 1 week, and that telangiectasia in the treatment group was markedly reduced compared with the control group at 4 weeks. The difference of the $\mathrm{L}$ and a values of lesions between the treatment and control group was significant $(\mathrm{P}<0.05)$. Overall, the present results
\end{abstract}

Correspondence to: Professor Tie-Chi Lei, Department of Dermatology, Renmin Hospital of Wuhan University, 99 Ziyang Road, Wuchang, Wuhan, Hubei 430060, P.R. China

E-mail: tiechilei@126.com

${ }^{*}$ Contributed equally

Key words: telangiectasia, timolol maleate, antibacterial peptides, kallikreins suggested that the abnormal expression of LL-37 may be one of the mechanisms underlying the pathogenesis of facial corticosteroid addiction dermatitis (FCAD) and TMEDs may inhibit the mRNA expression of LL-37 by downregulating KLK5; in this regard, TMEDs may serve a role in attenuating telangiectasia, which may be beneficial in improving the telangiectasia symptoms of FCAD.

\section{Introduction}

Facial corticosteroid addiction dermatitis (FCAD) is a relatively uncontrollable dermatological condition that results from long-term abuse of topical steroids. FCAD takes the form of a recurring and exacerbated dermatitis with marked redness, exuding, scaling, crusting, burning and telangiectasias, and the condition affects the facial appearance and quality of life of the patients (1). Topical steroid abuse may lead to 2 principal problems, which lie at the opposing ends of the psychosomatic spectrum. Topical corticosteroid phobia, which lies at the opposite end of the psychiatric spectrum of steroid abuse, has been reported particularly among parents of atopic children (2). However, FCAD has received little attention in medical publications. Australian general practitioners have come into contact with patients who have read material or watched videos on this condition (3). Due to improper steroid use, the incidence of FCAD appears to be constantly increasing in China and India (4). Data from China have indicated that FCAD is the fifth principal skin disease following eczema, psoriasis, acne and urticaria. The reasons for this increase in the incidence of FCAD include non-standard clinical management, regulatory loopholes that enable beauty salons to use corticosteroids inappropriately, widespread availability of corticosteroids, and poor understanding of the appropriate use of corticosteroids among patients (5). Therefore, it is necessary to identify more effective and appropriate treatment strategies for the condition. The common treatments for FCAD include avoidance of the application of topical steroids, use of a topical calcineurin antagonist and antihistamines. These treatments may be useful to a certain extent; however, topical irritation and fluctuating therapeutic effects limit their application (5). It appears that the biological effects of low-level light therapy may inhibit the local inflammation of FCAD, thereby relieving facial symptoms and gradually restoring barrier function in the affected facial skin. However, the telangiectasia caused 
by topical corticosteroids is difficult to alleviate $(4,6)$. The mechanism is considered to be one of vasoconstriction/vasodilatation that occurs secondary to the corticosteroids via a non-intact dermal barrier (7).

Timolol is a medication administered orally or as eye drops. It is a non-selective and powerful $\beta$-blocker used to treat ocular hypertension, angina, tachycardia and glaucoma (8). In recent years, timolol solution has been used by dermatologists to treat infant hemangioma (9). In the present study, the effects of timolol maleate $(0.5 \%)$ eye drops (TMEDs) in patients with FCAD and a rabbit model of telangiectasia were documented. To investigate the mechanism of action of timolol maleate, the mRNA expression of the antimicrobial peptides 37-amino acid peptide (LL-37) and kallikrein-5 (KLK5) was detected in tissues.

\section{Materials and methods}

Primary compounds and instruments. A precision chromameter (100 series) was purchased from Shenzhen EnChi Technology Co., Ltd. (Shenzhen, China). A hand-held dermatoscope (DermLite DL1) was obtained from Beijing Dermat Speedy Recovery T\&D Co., Ltd. (Beijing, China). Centrifuge tubes $(2.0 \mathrm{ml})$ were purchased from Corning Incorporated (Corning, NY, USA). Flumethasone ointment (0.02\%; $15 \mathrm{~g}$ ) was obtained from Shenzhen Jian An Pharmaceutical, Co., Ltd. (Shenzhen, China). TMEDs $(10 \mathrm{ml})$ were obtained from Chaoju Ophthalmology Hospital (Baotou, China). Additionally, $10 \mathrm{~g} 0.1 \%$ tacrolimus ointment was purchased from Astellas Pharmaceutical, Inc. (Beijing, China). The primers used for the synthesis of the antibacterial peptides LL-37 and KLK5 were purchased from Tsingke Biological Technology, Co., Ltd. (Beijing, China). A fluorometric quantitative-polymerase chain reaction (qPCR) system (7900/ViiA7 ${ }^{\mathrm{TM}}$ ) was obtained from Guangzhou Dongsheng Biotech Co., Ltd (Guangzhou, China). A horizontal electrophoresis apparatus (JY300) and an ultraviolet analyzer (JY02S) were purchased from Beijing Junyi Electrophoresis Co., Ltd. (Beijing, China). A Prime Script ${ }^{\circledR}$ Reverse Transcription reagent kit (cat. no. 252250AX) was obtained from Takara Biotechnology Co., Ltd. (Dalian, China) and TRIzol ${ }^{\circledR}$ reagent was from Invitrogen (Thermo Fisher Scientific, Inc., Waltham, MA, USA).

Establishment of the telangiectasia model in the inner ears of rabbits and drug intervention. A total of 50 healthy 16- to 20-week-old female Japanese White rabbits (weight $\sim 3 \mathrm{~kg}$ ) were purchased from the Baotou Medical College animal facility center (Baotou, China). All experiments were performed according to the guidelines of the National Institutes of Health (10) and the protocol was approved by the Institutional Animal Care and Use committee of Wuhan University Laboratory Animal Research Center (Wuhan, Hubei, China; permit no. 11203A). All of the rabbits were kept under the following conditions: Standard pelleted diet (125 g/day) with water ad libitum; room temperature at $16-28^{\circ} \mathrm{C}$; humidity $40-70 \%$; ventilation with $10-15$ air changes per h; noise $\leq 60 \mathrm{~dB}$; and 12-h light/dark cycle. The inner ear skin of rabbits was selected as the test region. The rabbits were randomly divided into three groups: Trial and negative control groups each with 20 animals, and a blank control group consisting of 10 animals. In the trial and negative control groups, the bilateral inner ears were marked with a circle of $2 \mathrm{~cm}$ diameter. Flumethasone $(0.02 \%)$ ointment was smeared in the marked circle twice daily for 6 weeks. Biopsies were taken following the 6 weeks administration period from 10 animals in each group. Subsequently, the remaining 10 animals in the trial group were treated with TMEDs, and animals in the negative group were treated with matrix ointment, twice daily for a further 6 weeks, following which biopsies were taken. In the blank control group, no drugs were applied to the rabbit ears. Biopsies were taken following 12 weeks and tissue samples were processed as described below. Detection of alterations in erythema, papules and telangiectasia were recorded using a hand-held dermatoscope.

Histopathological alterations. The lesions in rabbit inner ears were disinfected with iodine 3 times, with the iodine subsequently wiped away; $3 \%$ pentobarbital sodium ear vein anesthesia was then administered at a dosage of $30 \mathrm{mg} / \mathrm{kg}$. The tissue samples were cut into $3 \mathrm{~mm}$ wide segments, and $50 \%$ of the tissue samples were routinely fixed with $10 \%$ neutral buffered formalin overnight at room temperature, then embedded in paraffin wax. Then, 3-4 $\mu \mathrm{m}$ thick sections were cut from the embedded blocks. The tissue sections were deparaffinized in xylene and rehydrated in graded alcohols. Subsequently, the sections were stained in hematoxylin solution for $5 \mathrm{~min}$ at room temperature, washed with running tap water for $1 \mathrm{~min}$, counterstained in eosin solution for $2 \mathrm{~min}$ and mounted under a coverglass with resinous medium. The pathological alterations were observed under light microscope at x 50-100 magnification. The other half of the tissue samples were placed in a $2.0-\mathrm{ml}$ centrifuge tube in liquid nitrogen for $20 \mathrm{~min}$, and stored at $-80^{\circ} \mathrm{C}$. Semi-quantitative reverse transcription (RT)-PCR and qPCR were used to detect mRNA expression of LL-37 and KLK5.

Semi-quantitative $R T-P C R$ and $q P C R$ procedures for measurement of LL-37 and KLK5 mRNA expression levels TRIzol ${ }^{\circledR}$ method for RNA extraction. Total RNA was extracted from cells with TRIzol ${ }^{\circledR}$ reagent (Lot: $252250 \mathrm{AX}$; Thermo Fisher Scientific Inc., Waltham, MA, USA). The fresh tissue stored at $-80^{\circ} \mathrm{C}$ was removed from refrigeration. Subsequently, $\sim 100 \mathrm{mg}$ was weighed out, and $1 \mathrm{ml} \mathrm{TRIzol}{ }^{\circledR}$ reagent added. The tissue was ground into a slurry with a homogenizer, placed into an Eppendorf tube without RNase and allowed to react with TRIzol ${ }^{\circledR}$ reagent for $10 \mathrm{~min}$. Following which, $200 \mu \mathrm{l}$ chloroform was added, followed by vigorous mixing numerous times and left for $5 \mathrm{~min}$ at room temperature. The mixture was centrifuged $\left(13,780 \mathrm{x} \mathrm{g}\right.$ for $15 \mathrm{~min}$ at $\left.4^{\circ} \mathrm{C}\right)$ to establish separate phases. The upper aqueous phase $(\sim 400 \mu \mathrm{l})$ was transferred to a new 1.5-ml Eppendorf tube. Isopropanol (400 $\mu \mathrm{l})$ was added, followed by mixing and standing at room temperature for $10 \mathrm{~min}$. Subsequent centrifugation $(13,780 \mathrm{x} \mathrm{g}$ for $10 \mathrm{~min}$ at $4^{\circ} \mathrm{C}$ ) isolated a white RNA precipitate at the bottom of the tube. The supernatant was discarded, and $1 \mathrm{ml}$ of $75 \%$ ethanol in RNase-free water was added, followed by vortex mixing and centrifugation $\left(11,483 \mathrm{x}\right.$ g for $5 \mathrm{~min}$ at $\left.4^{\circ} \mathrm{C}\right)$; this step was then repeated. The supernatant was discarded, the RNA was dried in air for 5-10 min, and the precipitate was dissolved in $20 \mu \mathrm{l}$ diethyl pyrocarbonate-treated water. The dissolved 
RNA $(2 \mu \mathrm{l})$ was used to detect the concentration and purity of the sample with a micro-spectrophotometer. The quantity of each RNA sample with a A260/A280 ratio between 1.8 and 2.2 was considered for suitable use. The concentration of the RNA in the sample was calculated, according to the optical density (OD) value using the following formula: Total RNA concentration $(\mu \mathrm{g} / \mu \mathrm{l})=\mathrm{OD} 260 \times 40 \times 200 \times 10^{-3}$. Finally, the total RNA was stored at $-80^{\circ} \mathrm{C}$.

$R T$ into cDNA. cDNA was reverse-transcribed using the PrimeScript ${ }^{\circledR}$ RT reagent kit (Takara Biotechnology Co., Ltd., Dalian, China). The primers used in the present study were: $\beta$-actin forward, 5'-CGCATGCAGAAGGAGATCAC-3' and reverse, 5'-CGACTCGTCATACTCCTGCT-3'; LL-37 forward, 5'-TTACGGTGAAGGAGACGGA-3' and reverse, 5'-CAG CGGATGTCAAAGGAGTC-3'; and KLK5 forward, 5'-GCC ACCATTCCATGTCACC-3' and reverse, 5'-GATGTTGAT GGCCTTGACCG-3'. The sizes were 162, 139 and $167 \mathrm{kDa}$, respectively. The reaction system comprised of RNA ( $2 \mu \mathrm{l}$; $2 \mu \mathrm{g})$, Oligo(dT)15 (10 $\mu \mathrm{M} ; 2 \mu \mathrm{l})$, dNTP (2.5 mM; $4 \mu \mathrm{l}), 5 \mathrm{X}$ HiScript Buffer $(4 \mu 1)$, HiScript Reverse Transcriptase $(1 \mu \mathrm{l})$, Ribonuclease Inhibitor $(0.5 \mu \mathrm{l})$ and double-distilled water $\left(\mathrm{ddH}_{2} \mathrm{O} ; \mathrm{RNase}-\mathrm{free} ; \leq 20 \mu \mathrm{l}\right)$. The reaction conditions were $25^{\circ} \mathrm{C}$ for $5 \mathrm{~min}, 50^{\circ} \mathrm{C}$ for $15 \mathrm{~min}, 85^{\circ} \mathrm{C}$ for $5 \mathrm{~min}$ and $4^{\circ} \mathrm{C}$ for $10 \mathrm{~min}$.

Semi-quantitative RT-PCR. The components were from a PrimeScript ${ }^{\circledR}$ RT kit (Takara Biotechnology Co., Ltd.). The reaction system comprised internal reference $\mathrm{F}(10 \mu \mathrm{M}$, $0.5 \mu \mathrm{l})$, internal reference $\mathrm{R}(10 \mu \mathrm{M}, 0.5 \mu \mathrm{l})$, dNTPs $(2.5 \mathrm{mM}$, $2 \mu \mathrm{l})$, Ex Taq $(0.25 \mu \mathrm{l}), 10 \mathrm{X}$ Ex Taq E Buffer $(2.5 \mu \mathrm{l})$, cDNA (1 $\mu \mathrm{l})$ and $\mathrm{ddH}_{2} \mathrm{O}(\leq 25 \mu \mathrm{l})$. The reaction conditions were: Pre-denaturation at $94^{\circ} \mathrm{C}$ for $4 \mathrm{~min}$, followed by denaturation at $94^{\circ} \mathrm{C}$ for $30 \mathrm{sec}$, annealing at $56^{\circ} \mathrm{C}$ for $30 \mathrm{sec}$, and extension at $72^{\circ} \mathrm{C}$ for $25 \mathrm{sec}$, for 30 cycles, with a final extension at $72^{\circ} \mathrm{C}$ for $4 \mathrm{~min}$. The PCR product was analyzed by $1 \%$ agarose gel electrophoresis and visualized by staining with ethidium bromide. The intensity of the bands was quantified using Image J version 1.51j8 (NIH, Bethesda, MD, USA).

qPCR. Two-fold dilutions of LL-37 and KLK5 cDNA were used. The reaction system comprised cDNA (two-fold dilution; $4 \mu \mathrm{l})$, forward primer $(100 \mu \mathrm{M} ; 0.4 \mu \mathrm{l})$, reverse primer $(100 \mu \mathrm{M} ; 0.4 \mu \mathrm{l}), \mathrm{SYBR}^{\circledR}$ Green/Fluorescein qPCR Master $\operatorname{mix}\left(2 \mathrm{X}, 10 \mu \mathrm{l}\right.$; Vazyme, Piscataway, NJ, USA) and $\mathrm{ddH}_{2} \mathrm{O}$ $(5.2 \mu \mathrm{l})$. The PCR reactions were conducted at $50^{\circ} \mathrm{C}$ for $2 \mathrm{~min}$, followed by $95^{\circ} \mathrm{C}$ for $10 \mathrm{~min}$, and 40 cycles of $95^{\circ} \mathrm{C}$ for $30 \mathrm{sec}$ and $60^{\circ} \mathrm{C}$ for $30 \mathrm{sec}$. Each individual qPCR assay had at $\geq 3$ replications. The final data were analyzed using the $2^{-\Delta \Delta \mathrm{Cq}}$ method (11).

Human samples. A total of 30 female patients (19-48 years) with a clinical diagnosis of FCAD were recruited from the Dermatology Department of Renmin Hospital of Wuhan University (Wuhan, China) between March and October 2016. Patients provided written informed consent, and the Ethical Committee of the Renmin Hospital of Wuhan University approved the present study and supervised its compliance with the Declaration of Helsinki Guidelines. The diagnostic inclusion criteria used for the present study were in accordance with the guidelines for the diagnosis and treatment of FCAD developed by the Chinese Physicians' Association in 2009 (12). The diagnostic criteria were as follows: i) Topical glucocorticoid preparations/beauty salon products/skincare products had been used for >1 month; ii) use of topical glucocorticoid preparations/beauty salon products/skincare products had led to aggravation of the original symptoms; however, they had been re-applied following symptom remission; iii) patients had 'skin thinning' or epidermal atrophy; iv) patients had telangiectasia; and v) lesions exhibited flushing, erythema, pimples or acne-like, rosacea-like dermatitis. If (i) and (ii) were satisfied, (iii)-(v) led to a diagnosis of FCAD.

The exclusion criteria were as follows: i) Patients with acne, rosacea, seborrheic dermatitis, facial disseminated miliary lupus or tinea; ii) allergies to the ingredients in the test product; iii) psychiatric disorders; iv) pregnancy; v) systemic lupus erythematosus or rheumatoid arthritis; vi) infection with human immunodeficiency virus; vii) patients who had been diagnosed with a skin tumor and had received treatment within the previous 12 months; viii) patients for whom glucocorticoids, immunosuppressant agents or anti-allergic drugs had been administered via oral or topical routes within 14 days of study commencement; or ix) use of other similar products currently or within 1 month prior to study commencement.

Alterations in skin lesions. On the right cheek of each patient with FCAD (treatment group), three drops of TMEDs were administered onto skin lesions, followed $30 \mathrm{~min}$ later by $0.1 \%$ tacrolimus ointment. This regimen was performed twice daily for 4 weeks. For the subsequent 4 weeks, TMEDs were applied twice daily and $0.1 \%$ tacrolimus ointment once daily. The left cheek of each patient with FCAD was used as the control, on which $0.1 \%$ tacrolimus ointment was applied twice daily for 4 weeks, and once daily for the subsequent 4 weeks. Lesions were observed by a handheld mirror prior to and at 1, 2, 4 and 8 weeks following treatment. The same background and bright lights were maintained to acquire images, and images were taken of the center of the cheeks each time. Simultaneously, the color of lesions was measured with a chroma meter. Values of L, a and b, based on the Commission Internationale de l'Éclairage (CIE) system (13), were measured 3 times and the mean values were calculated. The $\mathrm{L}$ value represents the balance from white to black, with pure black being 0 and pure white being 100 . If the $\mathrm{L}$ value is high, the color is close to white. If the $\mathrm{L}$ value is small, the color is close to black. The a value represents the balance from red to green, between a range of +60 to -60 . A positive value indicates the red direction, and a negative value indicates the green direction. The b value represents the balance from yellow to blue, additionally between a range of +60 to -60 . A positive value indicates the yellow direction, and a negative value indicates the blue direction. During the course of treatment, if a burning sensation, pain or dryness were experienced, $3 \%$ boric acid solution was applied for $20 \mathrm{~min}$ for 3-5 days. Additionally, biofilms containing hyaluronic acid were available to be used in cases of skin dryness to aid facial moisturizing.

Statistical analysis. SPSS software version 22.0 (IBM Corp., Armonk, NY, USA) was used for analysis of all measurement data. Data are expressed as the mean \pm standard deviation. 
A

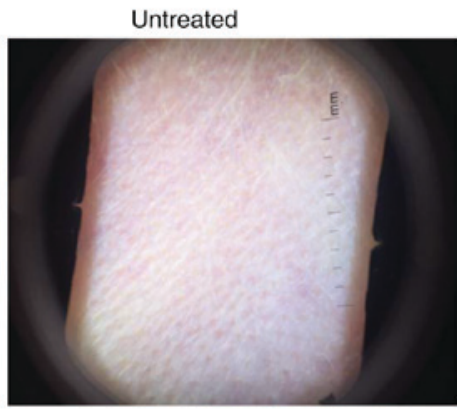

B
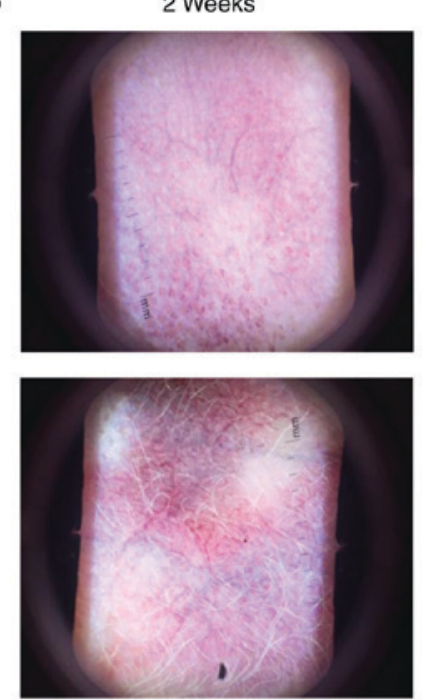
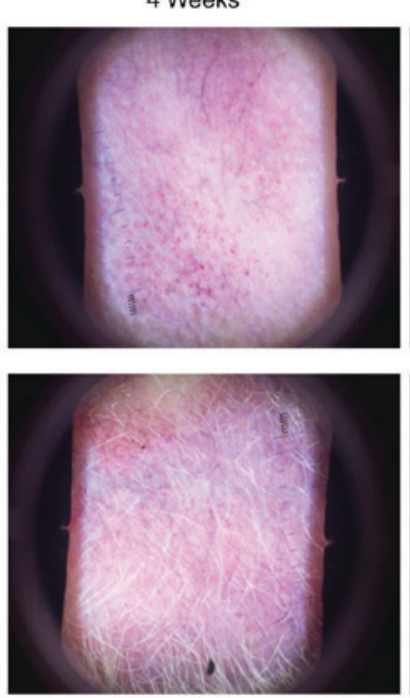

$0.02 \%$ flumethasone/ 6 Weeks

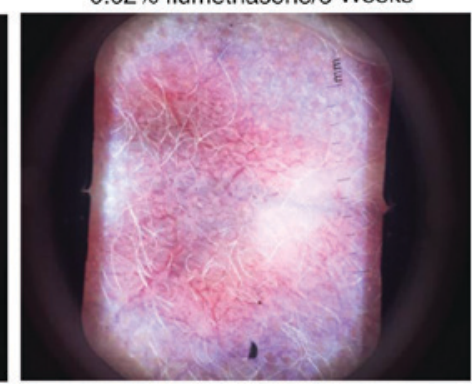

6 Weeks
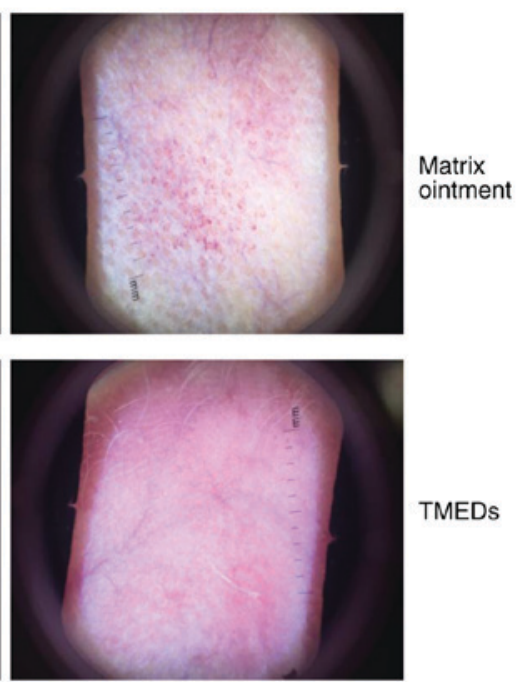

Figure 1. Pathological alterations in rabbit ears, according to dermoscopy. (A) Erythema and telangiectasia were evident with flumethasone ointment treatment at 6 weeks when compared with untreated rabbit ears. (B) Different alterations of rabbit ears at different times following TMEDs application (trial group) and matrix ointment (negative control group). The erythema and capillaries began to fade after 2 weeks of TMEDs application, the regression was evident at 4 weeks, and there was marginal expansion of the capillaries after 6 weeks of TMEDs application. Erythema and capillary dilation were not significantly altered with matrix ointment treatment. TMEDs, timolol maleate $(0.5 \%)$ eye drops.

Student's t-test was used to compare values between groups. Variation of each indicator over time was analyzed by two-way analysis of variance. Repeated measurement analysis of variance was followed by the Bonferroni's correction. The data shown represent the mean values obtained from 3 independent experiments. $\mathrm{P}<0.05$ was considered to indicate a statistically significant difference.

\section{Results}

Alterations in rabbit ears, according to dermoscopy. The trial (TMEDS) and negative control (matrix ointment) groups were treated with $0.02 \%$ flumethasone ointment twice daily for 6 weeks (Fig. 1). Erythema and a small amount of telangiectasia were observed weekly, and there were evident signs of erythema and telangiectasia at 6 weeks in the 2 groups. The blank control group exhibited no erythema or telangiectasia (Fig. 1A). In the trial group, TMEDs were continuously smeared, while the negative group was treated with matrix ointment, respectively, twice daily for 6 weeks. Compared with the negative control group, erythema and telangiectasia had marginally dissipated following 2 weeks of application in the trial group, regression was more evident at 4 weeks, and erythema and telangiectasia were reduced markedly following 6 weeks of continuous application in the trial group, leaving a small expansion of the capillaries (Fig. 1B). Marked erythema and expansion of the capillaries were still visible in the negative control group applied with matrix ointment. In the animal experiments, it was observed that the overall skin color of TEMDs-treated group appeared to be redder compared with negative control. It cannot be completely excluded that TMEDs exerts a mild irritant effect on rabbit ear skin.

Histopathology of rabbits. The inner skin of the rabbit ears was continuously treated with the flumethasone compound ointment for 6 weeks (Fig. 2). The trial and negative control groups exhibited a marked inflammatory response when compared with the blank control group (Fig. 2A). Histopathology identified hyperkeratosis, atrophy of the epidermis, vasodilatation of the dermis and luminal congestion, and infiltration of lymphocytes. In the trial group, histopathology identified marked atrophy, and mild vasodilation and hyperemia compared with the negative control group following treatment with TMEDs for 6 weeks (Fig. 2B). There were no significant alterations prior to and following treatment in the negative control group (Fig. 2C).

Gel electrophoresis determines LL-37 and KLK5 expression. PCR product $(10 \mu \mathrm{l})$ was observed using $1 \%$ agarose gel electrophoresis (Fig. 3). Rabbit $\beta$-actin exhibited a clear target band 
A

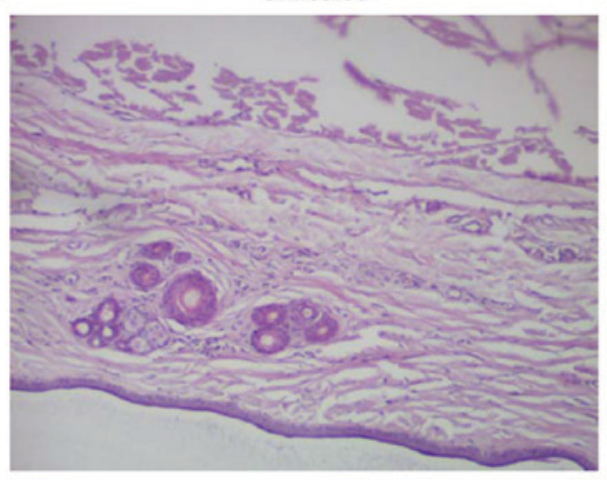

B

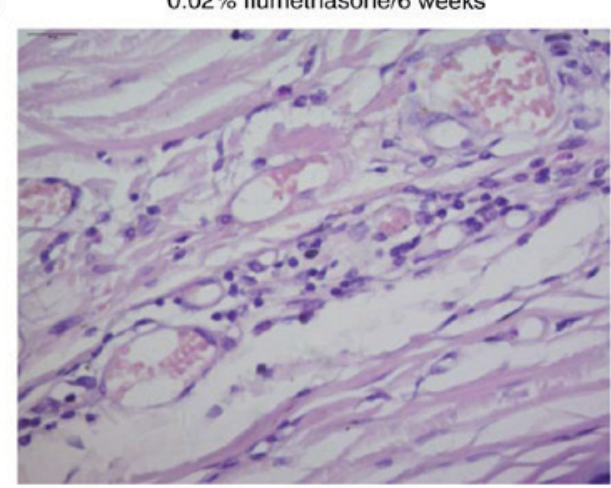

C

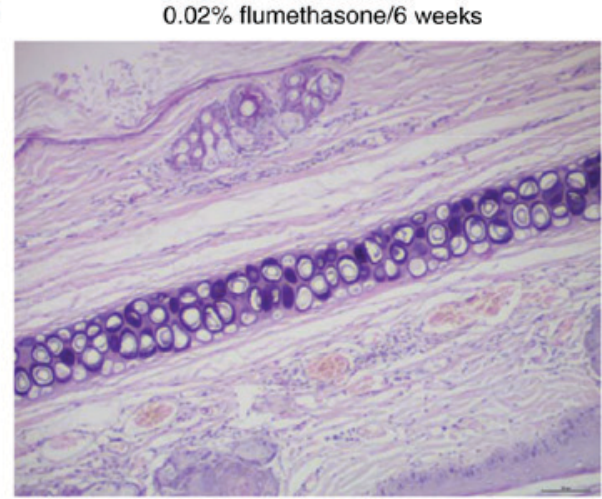

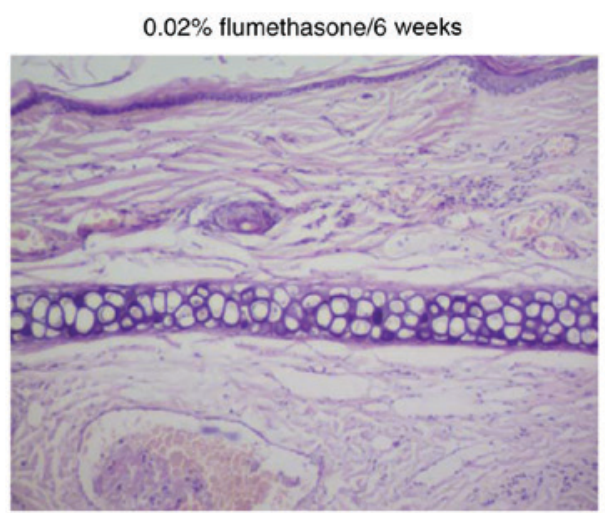
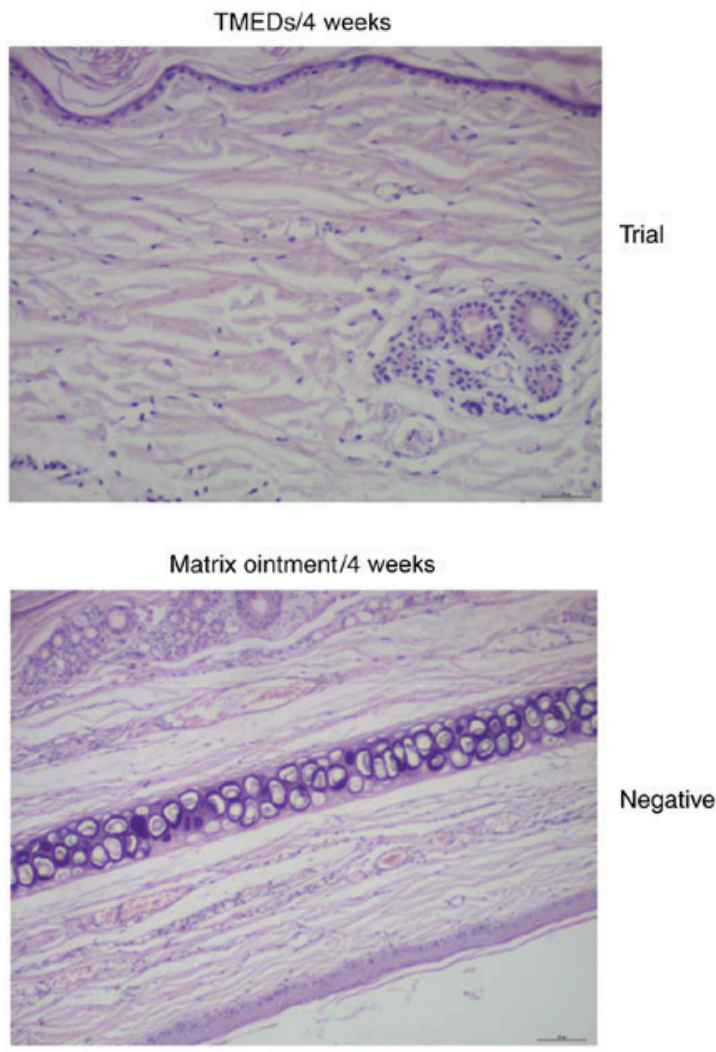

Figure 2. Histopathology of rabbit ears with telangiectasia pre- and post-treatment. (A) Mild hyperkeratosis, epidermis atrophy, mild atrophy of the dermal layer, congested capillaries, dilatation and perivascular infiltration of inflammatory cells were evident with flumethasone treatment at 6 weeks when compared with untreated rabbit ears (magnification, x100). (B) Histopathology identified congestion of the dermal capillaries, dilatation and perivascular infiltration of lymphocytes (magnification, x400). Epidermal atrophy, mild vascular dilatation and congestion in the superficial dermal layer, and a small number of inflammatory cells were observed following application of TMEDs in the trial group (magnification, x100). (C) The negative control group exhibited mild hyperkeratosis, congested capillaries, dilatation and perivascular infiltration of inflammatory cells pre- and post-treatment (magnification, x100). TMEDs, timolol maleate $(0.5 \%)$ eye drops.

of $\sim 160 \mathrm{kDa}$. LL-37 was visible as a target band at $\sim 140 \mathrm{kDa}$, and KLK5 at $\sim 170 \mathrm{kDa}$ (Fig. 3A). mRNA expression of LL-37 and KLK5 was the highest in the negative control group, with successively lower levels detected in the model group and the blank control group (Fig. 3B). These results suggested that the mRNA expression of LL-37 and KLK5 in telangiectasia lesions in rabbits increased significantly, and subsequently decreased, following 6 weeks of treatment with TMEDs; however, it remained higher compared with normal tissues.

Clinical observations. The data presented in Fig. 4 depicts representative patient images of the left and right sides of the face, assigned to the treatment and control groups, respectively.
Erythema on the two cheeks was visible to the naked eye after 1 week. Dermoscopy revealed marked telangiectasia and congestion, and there were no evident differences between the two groups following treatment for 1 week. Erythema on the cheeks was improved markedly at 2 weeks, although the skin on the left cheek improved more notably. Dermoscopy also demonstrated considerable reduction in inflammation on the left cheek, and the number of telangiectasias was marginally reduced. The right cheek exhibited considerably reduced inflammation; however, telangiectasia was not markedly improved. There were more evident differences between the cheeks at 4 weeks; erythema had disappeared, and dermoscopy identified a considerable reduction in the number of telangiectasias in the treatment 


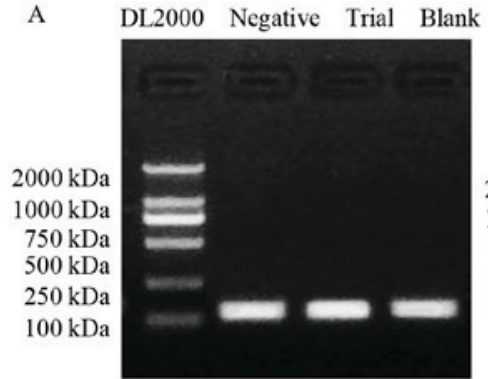

Rabbit $\beta$-actin

B

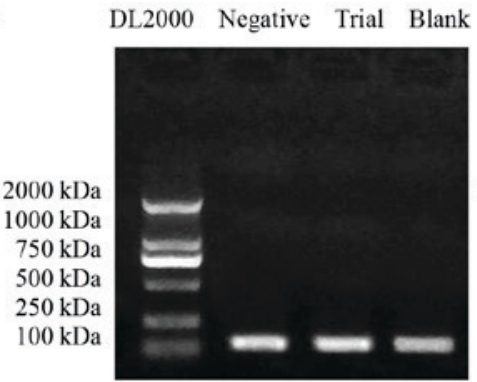

Rabbit LL-37

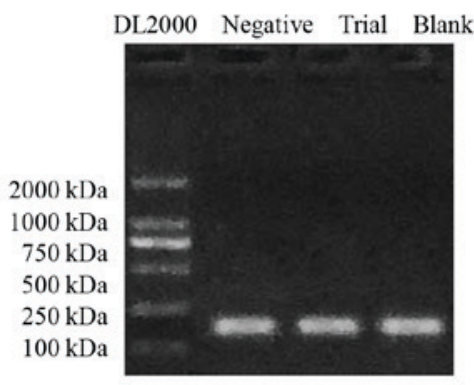

Rabbit KLK5

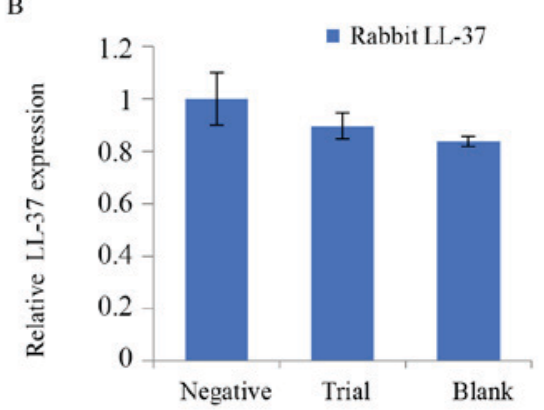

C

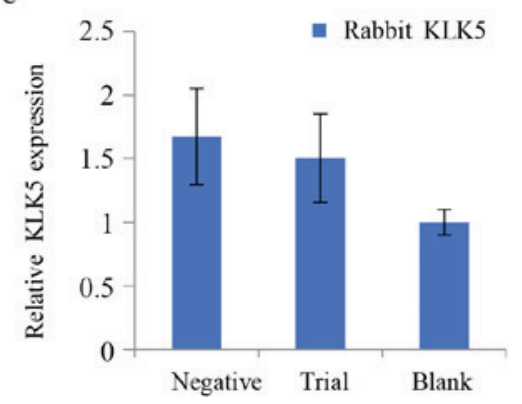

Figure 3. Gel electrophoresis was conducted to measure LL-37 and KLK5 expression. (A) Semi-quantitative reverse transcription-polymerase chain reaction expression of rabbit $\beta$-actin, rabbit LL-37 and rabbit KLK5. The intensity of the bands was quantified using Image J software. The housekeeping gene $\beta$-actin was used for normalizing mRNA levels. Relative expression of (B) rabbitLL-37 or (C) rabbit KLK5 was obtained from 3 individual experiments. LL-37, 37-amino acid peptide; KLK5, kallikrein-5.

group, while alterations in the control group were less evident. Bilateral erythema appeared to have regressed upon visual observation at 8 weeks. Dermoscopy revealed that the majority of the telangiectasias had subsided in the treatment group, while the telangiectasias in the control group remained clearly visible.

Alterations in the values of $L, a$ and $b$. Results demonstrated that the effect of time on $\mathrm{L}$ and a values were significant in the treatment and control groups $(\mathrm{P}<0.001)$. Following Bonferroni's correction, differences between these groups remained significant $(\mathrm{P}<0.05)$. $\mathrm{L}$ and a values were significant in the treatment and control groups $(\mathrm{P}<0.05)$. Additionally, the interaction of $\mathrm{L}$ and a values between Time and Group was significant $(\mathrm{P}<0.001)$. Therefore, a simple effect test was conducted to compare the differences between the mean values at each time point to determine the effect of intervention. The Student's t-test was employed for comparisons between the groups at each time point. However, the $\mathrm{b}$ value did not differ significantly $(\mathrm{t}=-2.061$; $\mathrm{P}=0.044)$. All results are listed in Tables I-III.

\section{Discussion}

Long-term topical application of corticosteroids may inhibit cellular DNA synthesis and mitosis. This leads to inhibition of proliferation and differentiation in keratinocytes, resulting in epidermal atrophy (14). Additionally, due to inhibition of proliferation in fibroblasts, collagen synthesis may be reduced, leading to the widening and expansion of dermal vessels. The reduction in the number of collagen fibers in the skin cortex additionally causes the blood vessels to become shallow and atrophy (15). As the adhesion between the collagen fibers of the dermis is reduced, blood vessels are observable at the skin surface, resulting from capillary dilatation and thinning of the skin $(5,16)$.
A number of studies have demonstrated that the earliest side effect of topical corticosteroids is skin atrophy, regardless of the dose or duration of topical glucocorticoid used. The severity of atrophy is associated with the dose of glucocorticoid, and telangiectasia and pigmentation may appear within 1 month (17). Sari et al (18) and Nicoli et al (19) demonstrated that the inner ears of rabbits have good hydrophilicity and lipophilicity, and may be used as effective models for transdermal administration of drugs. In the present study, the pathological images of rabbit ear tissue exhibited evident vasodilation, congestion and epidermal atrophy upon application of a glucocorticoid, which was consistent with the studies aforementioned.

Previous reports have suggested that hemangioma may be observed 4 weeks following the application of timolol solution; however, the tumor color fades significantly by 16 weeks (20). Timolol solution is favored by clinicians as its topical application is safe and effective (21). Based on this, it was speculated that topical application of timolol solution may be effective for improving telangiectasia. In the present study, topical treatment with TMEDs combined with tacrolimus ointment in patients with FCAD resulted in a marked improvement of erythema and telangiectasia after 4 weeks. The majority of the expanded capillaries subsided markedly after 8 weeks of treatment, which was a marked improvement over the use of tacrolimus ointment alone. Notably, TMEDs were safe and effective without causing evident discomfort during treatment.

Previously, alterations in skin color have been observed primarily by the naked eye, a method that is susceptible to subjectivity. Studies on skin color observations outside of China tend to be more non-invasive $(22,23)$. The measurement results are typically expressed according to the CIE L*a*b color system (13). The $\mathrm{L}$ value is positively associated with the levels of melanin in the skin and hemoglobin in the dermis. The a value indicates the 


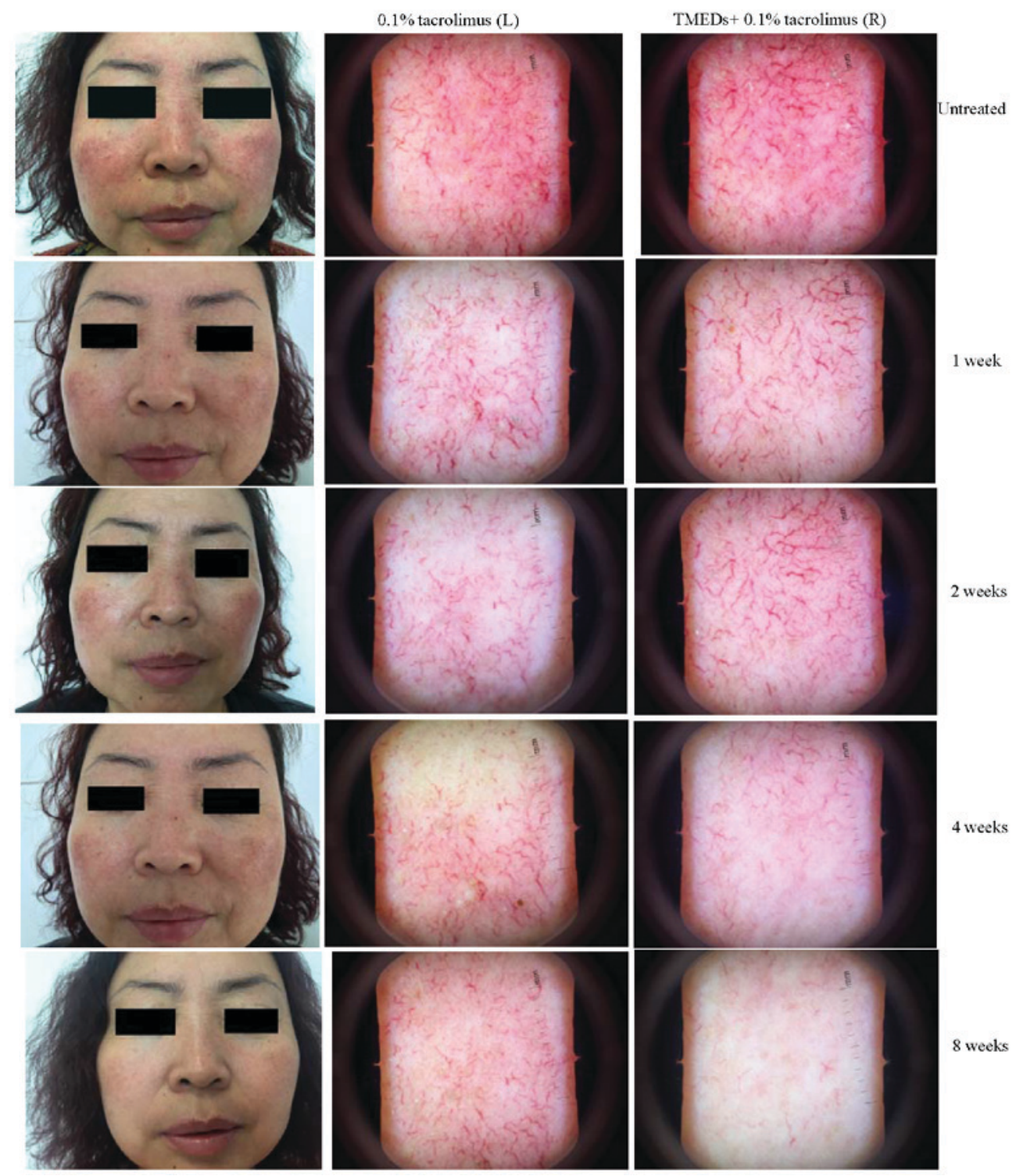

Figure 4. Clinical observations of a 46-year-old woman, suffering from facial corticosteroid addiction dermatitis. The left side of the face observed by dermoscopy at 1,2, 4 and 8 weeks following $0.1 \%$ tacrolimus application (negative control group). The right side of the face observed by dermoscopy (magnification, $\mathrm{x} 50$ ) at 1,2,4 and 8 weeks following TMEDs combined with $0.1 \%$ tacrolimus application (treatment group). TMEDs, timolol maleate (0.5\%) eye drops; L, left; R, right.

degree of redness of the skin, which is positively associated with hemoglobin content. The larger the a value, the redder the skin color. The $\mathrm{b}$ value represents the balance from yellow to blue, also between a range of +60 to -60 . A positive value indicates the yellow direction, and a negative value indicates the blue direction. In the present study, there was no significant difference in the $b$ value between the treatment group and the control group, which suggested that there was no significant correlation between the $b$ value and the color alteration of the capillary dilatation lesions. However, alterations in the $b$ value with regard to skin color require further investigation.

The primary alterations in the values of $\mathrm{L}$ and a were measured. Significant differences between these two indices were identified between the two groups. The difference between the treatment and control groups was significant, whereas that for the $b$ value was not. These results suggest that use of a spectrophotometer may be more accurate and objective compared with the naked eye to observe skin color; however, dermoscopy serves as an additional tool for effectively detecting subtle changes in skin color.

Antibacterial peptides have been a focus of research in recent years. Antibacterial peptides are expressed in mammals, birds and fish. They serve central roles in the natural immune response of the skin, which has been demonstrated in numerous animal and disease models, including those of rosacea, acne, atopic dermatitis, psoriasis and other inflammatory dermatoses (24-26). Antibacterial peptides may stimulate leukocyte chemotaxis, angiogenesis, and the expression of extracellular matrix components, which are involved in the clinical manifestations of erythema, papules and telangiectasia (26). The same is true for the clinical manifestations of FCAD, which suggests that antimicrobial peptides may additionally be present in FCAD lesions due to hormone-dependent dermatitis. A key human antimicrobial peptide is $18 \mathrm{kDa}$ cationic antimicrobial protein (CAP18). CAP18 must be cleaved from its C-terminus by KLK 5 hydrolysis to release the active fragments that exert 
Table I. L values in the two groups $(\mathrm{n}=30)$.

\begin{tabular}{|c|c|c|c|c|c|c|c|c|}
\hline \multirow[b]{2}{*}{ Group } & \multirow[b]{2}{*}{ Pre-treatment } & \multirow[b]{2}{*}{1 week } & \multirow[b]{2}{*}{2 weeks } & \multirow[b]{2}{*}{4 weeks } & \multirow[b]{2}{*}{8 weeks } & \multicolumn{3}{|c|}{ P-value } \\
\hline & & & & & & Group & Time & Group x time \\
\hline Treatment & $54.64 \pm 5.72$ & $57.18 \pm 5.33^{\mathrm{a}}$ & $58.68 \pm 5.14^{\mathrm{a}, \mathrm{b}}$ & $60.72 \pm 5.12^{\mathrm{a}-\mathrm{c}}$ & $62.46 \pm 5.10^{\mathrm{a}-\mathrm{d}}$ & 0.031 & $<0.001$ & $<0.001$ \\
\hline Control & $54.25 \pm 4.77$ & $55.08 \pm 4.65^{\mathrm{a}}$ & $55.98 \pm 4.67^{\mathrm{a}, \mathrm{b}}$ & $56.82 \pm 4.61^{\mathrm{a}-\mathrm{c}}$ & $57.42 \pm 4.49^{\mathrm{a}-\mathrm{d}}$ & - & $<0.001$ & - \\
\hline t-value & 0.286 & 1.625 & 2.132 & 3.100 & 4.063 & - & - & - \\
\hline P-value & 0.776 & 0.110 & 0.037 & 0.003 & $<0.001$ & - & - & - \\
\hline
\end{tabular}

The $\mathrm{L}$ value represents the balance from white to black, with pure black being 0 and pure white being 100 . ${ }^{\mathrm{a}} \mathrm{P}<0.05 \mathrm{vs}$. pre-treatment; ${ }^{\mathrm{b}} \mathrm{P}<0.05$ vs. 1 week post-treatment; ${ }^{\mathrm{C}} \mathrm{P}<0.05$ vs. 2 weeks post-treatment; ${ }^{\mathrm{d}} \mathrm{P}<0.05$ vs. 4 weeks post-treatment.

Table II. Analysis of variance of a values between the two groups $(n=30)$.

\begin{tabular}{|c|c|c|c|c|c|c|c|c|}
\hline \multirow[b]{2}{*}{ Group } & \multirow[b]{2}{*}{ Pre-treatment } & \multirow[b]{2}{*}{1 week } & \multirow[b]{2}{*}{2 weeks } & \multirow[b]{2}{*}{4 weeks } & \multirow[b]{2}{*}{8 weeks } & \multicolumn{3}{|c|}{ P-value } \\
\hline & & & & & & Group & Time & Group $\mathrm{x}$ time \\
\hline Treatment & $13.97 \pm 2.45$ & $13.12 \pm 2.29^{a}$ & $11.67 \pm 1.95^{\mathrm{a}, \mathrm{b}}$ & $10.37 \pm 1.71^{\mathrm{a}-\mathrm{c}}$ & $9.11 \pm 1.96^{\mathrm{a}-\mathrm{d}}$ & 0.002 & $<0.001$ & $<0.001$ \\
\hline Control & $14.38 \pm 2.23$ & $13.85 \pm 2.1^{\mathrm{a}}$ & $13.14 \pm 1.95^{\mathrm{a}, \mathrm{b}}$ & $12.52 \pm 2.03^{\mathrm{a}-\mathrm{c}}$ & $12.09 \pm 1.88^{\mathrm{a}-\mathrm{d}}$ & - & $<0.001$ & - \\
\hline t-value & -0.681 & -1.293 & -2.919 & -4.436 & -6.000 & - & - & - \\
\hline P-value & 0.499 & 0.201 & 0.005 & $<0.001$ & $<0.001$ & - & - & - \\
\hline
\end{tabular}

The a value represents the balance from red to green, within the range +60 to -60 . ${ }^{\text {a }}<0.05$ vs. pre-treatment; ${ }^{\text {b }} \mathrm{P}<0.05$ vs. 1 week post-treatment; ${ }^{\mathrm{c}} \mathrm{P}<0.05$ vs. 2 weeks post-treatment; ${ }^{\mathrm{d}} \mathrm{P}<0.05$ vs. 4 weeks post-treatment.

Table III. Analysis of variance of $b$ values between the two groups ( $n=30)$.

\begin{tabular}{lcccccccc}
\hline & & & & & & \multicolumn{2}{c}{ P-value } \\
\cline { 5 - 9 } Group & Pre-treatment & 1 week & 2 weeks & 4 weeks & 8 weeks & Group & Time & Group x time \\
\hline Treatment & $10.59 \pm 2.45$ & $11.52 \pm 2.35^{\mathrm{a}}$ & $12.87 \pm 2.01^{\mathrm{a}, \mathrm{b}}$ & $14.22 \pm 2.01^{\mathrm{a}-\mathrm{c}}$ & $15.31 \pm 1.82^{\mathrm{a}-\mathrm{d}}$ & 0.260 & $<0.001$ & $<0.001$ \\
Control & $11.79 \pm 2.04$ & $12.73 \pm 1.84^{\mathrm{a}}$ & $13.5 \pm 1.77^{\mathrm{a}, \mathrm{b}}$ & $14.26 \pm 1.61^{\mathrm{a}-\mathrm{c}}$ & $14.96 \pm 1.51^{\mathrm{a}-\mathrm{d}}$ & - & $<0.001$ & - \\
t-value & -2.061 & -2.222 & -1.282 & -0.070 & 0.813 & - & - & - \\
P-value & 0.044 & 0.030 & 0.205 & 0.944 & 0.420 & - & - & - \\
\hline
\end{tabular}

The $b$ value represents the balance from yellow to blue, within the range +60 to -60 . ${ }^{\mathrm{a}} \mathrm{P}<0.05 \mathrm{vs}$. pre-treatment; ${ }^{\mathrm{b}} \mathrm{P}<0.05$ vs. 1 week post-treatment; ${ }^{\mathrm{c}} \mathrm{P}<0.05$ vs. 2 weeks post-treatment; ${ }^{\mathrm{d}} \mathrm{P}<0.05$ vs. 4 weeks post-treatment.

biological effects. LL-37 is a common antimicrobial peptide fragment with biological activity (27). In mice, infiltration of neutrophils, thrombosis and hemorrhage have been observed $48 \mathrm{~h}$ after subcutaneous administration of LL-37 (20 $\mu \mathrm{M})(28)$. In the rabbit model used in the present study, RT-PCR demonstrated that LL-37 expression in telangiectasia tissues was higher when compared with normal tissues, and that LL-37 expression was reduced in tissues treated with TMEDs; however, it remained higher compared with normal tissue, which was consistent with clinical manifestations. KLK5 is a key enzyme that regulates conversion of CAP18 to LL-37. The present results additionally demonstrated that KLK5 expression was reduced in telangiectasia tissues following administration of TMEDs.
It was reported that LL-37 has been involved in the occurrence and development of inflammatory skin diseases, including rosacea and psoriasis (29). The present study demonstrated that abnormal expression of LL-37 may be one of the mechanisms of pathogenesis of FCAD. LL-37 serves an important role in the development of acquired immunity of FCAD. TMEDs may reduce the expression of LL-37 mRNA by inhibiting the KLK5 mRNA and reducing the effect of anti-inflammatory and contractile capillaries. TMEDs are safe to improve flushing and telangiectasia of FCAD.

In conclusion, the present study may initially conclude that local topical timolol may improve glucocorticoid-induced telangiectasia symptoms, which may be beneficial in alleviating the telangiectasia symptoms of FCAD. 


\section{Acknowledgements}

Not applicable.

\section{Funding}

No funding was received.

\section{Availability of data and materials}

The datasets used and/or analyzed during the present study are available from the corresponding author on reasonable request.

\section{Authors' contributions}

YL performed the experiments. YL and XC analyzed the data. YL wrote the paper. TL conceived and designed the research. All authors read and approved the final manuscript.

\section{Ethics approval and consent to participate}

All experiments were performed according to the guidelines of the National Institutes of Health and the protocol was approved by the Institutional Animal care and Use Committee of Wuhan University Laboratory Animal Research Center (Wuhan, China; permit no. 11203A) The Ethical Committee of the Renmin Hospital of Wuhan University approved the present study and supervised its compliance with the Declaration of Helsinki Guidelines. Written informed consent was obtained from all participants.

\section{Patient consent for publication}

Patients provided written informed consent, agreeing for the publication of any associated data and images.

\section{Competing interests}

The authors declare that they have no competing interests.

\section{References}

1. Hajar T, Leshem YA, Hanifin JM, Nedorost ST, Lio PA, Paller AS, Block J and Simpson EL; (The National Eczema Association Task Force): A systematic review of topical corticosteroid withdrawal ('steroid addiction') in patients with atopic dermatitis and other dermatoses. J Am Acad Dermatol 72: 541-549.e2, 2015.

2. Ghosh A, Sengupta S, Coondoo A and Jana AK: Topical corticosteroid addiction and phobia. Indian J Dermatol 59: 465-468, 2014

3. Sheary B: Topical corticosteroid addiction and withdrawal-An overview for GPs. Aust Fam Physician 45: 386-388, 2016.

4. Luan Q, Liu L, Wei Q and Liu B: Effects of low-level light therapy on facial corticosteroid addiction dermatitis: A retrospective analysis of 170 Asian patients. Indian J Dermatol Venereol Leprol 80: 194, 2014

5. Lu H, Xiao T, Lu B, Dong D, Yu D, Wei H and Chen HD: Facial corticosteroid addictive dermatitis in Guiyang City, China. Clin Exp Dermatol 35: 618-621, 2010.

6. Goldman D: Tacrolimus ointment for the treatment of steroid-induced rosacea: A preliminary report. J Am Acad Dermatol 44: 995-998, 2001

7. Rapaport MJ and Lebwohl M: Corticosteroid addiction and withdrawal in the atopic: The red burning skin syndrome. Clin Dermatol 21: 201-214, 2003.

8. Sharifi M, Koch JM, Steele RJ, Adler D, Pompili VJ and Sopko J: Third degree AC block due to ophthalmic timilol solution. Int J Cardiol 80: 257-259, 2001.
9. Ng MSY, Tay YK, Ng SS, Foong AYW and Koh MJ: Comparison of two formulations of topical timolol for the treatment of infantile hemangiomas. Pediatr Dermatol 34: 492-493, 2017.

10. Sushma NJ, Priyanka S and Rao J: Neuroprotective role of melantonin against aluminum-induced oxidative stress in the hippocampus of mouse brain. J Appl Pharm Sci 1: 126-133, 2011.

11. Livak KJ and Schmittgen TD: Analysis of relative gene expression data using real-time quantitative PCR and the 2(-Delta Delta C(T)) method. Methods 25: 402-408, 2001.

12. Chinese Medical Association dermatology branch beauty professional group: Diagnosis and treatment guidelines of Corticosteroid addictive dermatitis. J Clin Dermatol 38: 549-550, 2009.

13. Jost S, Cauwerts C and Avouac P: CIE 2017 color fidelity index Rf: A better index to predict perceived color difference? J Opt Soc Am A Opt Image Sci Vis 35: B202-B213, 2018.

14. Barnes L, Kaya G and Rollason V: Topical corticosteroid-induced skin atrophy: A comprehensive review. Drug Saf 38: 493-509, 2015.

15. Inoue $\mathrm{Y}$, Isobe $\mathrm{M}$, Shiohara $\mathrm{T}$ and Hayashi $\mathrm{H}$ : Inhibitory activity of CX-659S, a novel diaminouracil derivative, against the rebound phenomenon following withdrawal of corticosteroid therapy for chronic contact hypersensitivity responses. Int Arch Allergy Immunol 131: 143-152, 2003.

16. Slominski AT, Manna PR and Tuckey RC: On the role of skin in the regulation of local and systemic steroidogenic activities. Steroids 103: 72-88, 2015.

17. Xiao Y and Wang J: Progress on the study of corticosteroid addictive dermatitis. J Yunnan Med 35: 380-382, 2014 (In Chinese).

18. Sari E, Bakar B, Dincel GC and Budak Yildiran FA: Effects of DMSO on a rabbit ear hypertrophic scar model: A controlled randomized experimental study. J Plast Reconstr Aesthet Surg 70: 509-517, 2017.

19. Nicoli S, Padula C, Aversa V, Vietti B, Wertz PW, Millet A, Falson F, Govoni P and Santi P: Characterization of rabbit ear skin as a skin model for in vitro transdermal permeation experiments: Histology, lipid composition and permeability. Skin Pharmacol Physiol 21: 218-226, 2008.

20. Hu L, Huang HZ, Li X, Lin XX and Li W: Open-label nonrandomized left-right comparison of imiquimod 5\% ointment and timolol maleate $0.5 \%$ eye drops in the treatment of proliferating superficial infantile hemangioma. Dermatology 230: 150-155, 2015.

21. Bhat YJ, Yaseen A and Hassan I: Topical timolol maleate: An effectual and safe recourse for infantile hemangiomas. Indian Dermatol Online J 7: 124-125, 2016

22. Aoki M, Akaishi S, Nakao J, Dohi T, Hyakusoku H and Ogawa R: Objective spectrometric measurement of keloid color in the East Asian population: Pitfalls of subjective color measurements. J Nippon Med Sch 83: 142-149, 2016.

23. Takiwaki H, Miyaoka Y, Kohno H and Arase S: Graphic analysis of the relationship between skin colour change and variations in the amounts of melanin and haemoglobin. Skin Res Technol 8: $78-83,2002$.

24. Thibaut de Menonville S, Rosignoli C, Soares E, Roquet M, Bertino B, Chappuis JP, Defoin-Platel/Chaussade C and Piwnica D: Topical Treatment of Rosacea with Ivermectin Inhibits Gene Expression of Cathelicidin Innate Immune Mediators, LL-37 and KLK5, in reconstructed and ex vivo skin models. Dermatol Ther (Heidelb) 7: 213-225, 2017.

25. Marcinkiewicz M and Majewski S: The role of antimicrobial peptides in chronic inflammatory skin diseases. Postepy Dermatol Alergol 33: 6-12, 2016.

26. Takahashi $\mathrm{T}$ and Gallo RL: The critical and multifunctional roles of antimicrobial peptides in dermatology. Dermatol Clin 35: 39-50, 2017.

27. Sakabe J, Umayahara T, Hiroike $M$, Shimauchi $T$, Ito $T$ and Tokura Y: Calcipotriol increases hCAP18 mRNA expression but inhibits extracellular LL37 peptide production in IL17/IL22-stimulated normal human epidermal keratinocytes. Acta Derm Venereol 94: 512-516, 2014.

28. Yamasaki K, Di Nardo A, Bardan A, Murakami M, Ohtake T, Coda A, Dorschner RA, Bonnart C, Descargues P, Hovnanian A, et al: Increased serine protease activity and cathelicidin promotes skin inflammation in rosacea. Nat Med 13: 975-980, 2007.

29. Bandurska K, Berdowska A, Barczyńska-Felusiak R and Krupa P. Unique features of human cathelicidin LL-37. Biofactors 41: 289-300, 2015

This work is licensed under a Creative Commons Attribution-NonCommercial-NoDerivatives 4.0 International (CC BY-NC-ND 4.0) License. 